\title{
UN NEGOCIO ENTRE PAISANOS: LOS TIANGUEROS PURÉPECHAS EN LA ZONA METROPOLITANA DE GUADALAJARA
}

\author{
Eugenia Bayona Escat
}

Resumen: Este artículo muestra la evolución y el desarrollo de la actividad del comercio informal que ha experimentado un grupo de inmigrantes purépechas en una colonia periférica de la Zona Metropolitana de Guadalajara. Se analizan conceptos clave como grupos corporativos, redes primarias y organización familiar $y$ del trabajo, que son necesarios para entender el proceso de asentamiento y captura del nicho laboral entre un grupo inmigrante y minoritario en el mundo urbano. El grupo corporativo se desarrolla basado en una especialidad comercial, aunque también gracias al mantenimiento de una serie de normas y valores que rigen los pioneros e inmigrantes con prestigio social.

Palabras clave: Inmigración purépecha, grupo corporativo, redes primarias, organización familiar y del trabajo.

Enviado a dictamen: 25 de noviembre de 2010

Aprobación: 16 de febrero de 2011

Revisiones: 1

Eugenia Bayona Escat. Profesora asociada en la Universidad de Valencia. Doctora en Ciencias Sociales, especialidad Antropología Social y Cultural. Centro de Investigaciones y Estudios Superiores en Antropología Social, Unidad Occidente, Guadalajara. Temas de especialización migración y género. Correo electrónico genybe@hotmail.com.
Abstract: The article shows the evolution and development of informal trade activity that has developed a group of immigrants in a colony Purépecha peripheral metropolitan area of Guadalajara. It discusses key concepts such as corporate groups, networks and organization primary family and work, which are necessary to understand the process of settlement and labor capture niche between a minority immigrant group in the urban world. The corporate group is developing a specialty based on commercial, but also by maintaining a set of rules and values that govern the pioneers and immigrants with social prestige.

Keywords: Purépecha immigration, corporate group, primary networks, family and work organization.

\section{Introducción}

$\mathrm{E}$ presente trabajo tiene como objetivo analizar el proceso de inserción laboral de un grupo de inmigrantes purépechas que proviene de la localidad de Pamatácuaro, en Michoacán, que desde hace más de tres décadas se ha trasladado a vivir a la Zona Metropolitana de Guadalajara (ZMG). ${ }^{1}$ La gran mayoría de los inmigrantes se dedican al comercio de menudeo en los mercados periféricos ambulantes conocidos como "tianguis", mientras unos pocos, los 
pioneros en el proceso migratorio y parientes cercanos de los mismos, se han establecido en el centro de la ciudad como comerciantes mayoristas. A lo largo de las dos últimas décadas, se ha desarrollado una extensa red de comerciantes mayoristas que proporcionan productos, trabajos y créditos a otros paisanos, lo que ha provocado la consolidación de un grupo corporativo de comerciantes paisanos, con normas y controles internos, que tiene el suficiente éxito como para que otros paisanos quieran probar suerte en la ciudad. ${ }^{2}$ Las redes entre vendedores purépechas se han diversificado a medida que el proceso migratorio ha ido en aumento, no obstante la compacta red comercial se mantiene gracias a la solidaridad y a la normatividad interna que mantienen sus miembros.

En el trabajo interesa examinar la evolución migratoria del grupo y las estrategias que se han utilizado para la captura y mantenimiento de la actividad comercial en la ciudad. Además, propongo indagar en las estructuras sociales y los mecanismos de control social que posibilitan que el grupo permanezca compacto, relacionado con el poder y prestigio de los pioneros del proceso migratorio y de otros inmigrantes vinculados por parentesco, y las consecuentes tensiones que suceden entre géneros, generaciones, e inmigrantes, fuera de los estratos con mayor influencia. La investigación se basa en un estudio empírico de primera mano realizado a través de entrevistas informales, trabajo de campo y observación participante, con inmigrantes que viven en la colonia El Campesino, del Barrio de Las Juntas y las Juntitas, en el municipio de Tlaquepaque, y que mantienen contactos con otros pamatacuarenses que residen en colonias cercanas del mismo municipio, como El Tapatío, Las Pintas, La Micaelita y La Mezquitera. ${ }^{3}$

La actividad más amplia se da en el análisis de los dos espacios principales por los que transitan los inmigrantes; la localidad de origen y la colonia de destino, para comprender las estructuras sociales que provienen del lugar natal y que se utilizan y se transforman para formar el grupo compacto y hermético urbano. El fenómeno migratorio de Pamatácuaro es mucho más complejo que el que se describe en este trabajo, de hecho hay inmigrantes que se han trasladado a otros lugares de la República mexicana: Uruapan, Zamora, Zacatecas y Monterrey, entre otros, e incluso a otros municipios alrededor de la ciudad de Guadalajara, lo que ha repercutido en el abandono paulatino de la localidad de origen. No obstante, los inmigrantes mantienen contactos con su lugar natal, a la vez que se han convertido en la fuente más importante de ingresos. Realizan constantes viajes de ida y vuelta: en celebraciones festivas anuales, cuando organizan bodas, comuniones y otros ritos de paso, además de conservar algunos cargos religiosos. También, en estas estancias temporales de los inmigrantes se inician noviazgos y se pactan bodas entre familias implicadas, se consolidan negocios y apoyos comerciales, se invierte el dinero ganado en el comercio urbano, y se fortalecen alianzas económicas y sociales entre parientes y paisanos. Por su parte, en la ciudad reciben visitas de familiares y de nuevos inmigrantes, celebran ritos comunales, algunos transformados y otros de reciente aparición, comentan noticias que van de un lado a otro, y se establece un tránsito de personas y recursos entre inmigrantes y no inmigrantes, en un territorio de identificación ampliado. (Ver mapa 1)

Los purépechas son un grupo numeroso entre la población indígena que reside en ZMG, junto a otros grupos que han ido aumentando en cifras en las últimas décadas. Si en el año 1990 se contabilizaban un total de 9,836 hablantes de alguna lengua indígena (de 5 y más años), esta cifra casi se duplica en diez años al llegar a 17,814 hablantes en el año 2000, con las lenguas indígenas más habladas de náhuatl, purépecha, mixteca, otomí, zapoteca, mazahua, huichol, maya y huasteca (INEGI, 1990, 2000). ${ }^{4}$ A pesar de que los datos censales no reportan la totalidad de inmigrantes indígenas que conviven en la ciudad, la cifra continúa subiendo en los últimos años, y según el Conteo de Población y Vivienda 
de INEGI 2005, en ZMG residen 19,990 hablantes. La lengua náhuatl continúa siendo la más numerosa, la purépecha se mantiene en segunda posición, y representa 13\% sobre el total de hablantes de lengua indígena, porcentaje que se mantiene igual con respecto al año 2000, muy por debajo de la cifra real, aunque demuestra su mantenimiento como grupo importante $y$, a la vez, confirma el aumento considerable de otros grupos indígenas en la ciudad. De lo datos censales se puede vislumbrar también que, a excepción del municipio de Tonalá, los inmigrantes indígenas se dispersan por toda ZMG con cifras elevadas en los tres municipios restantes, y un ligero incremento en los últimos años de desplazamiento hacia los municipios conurbanos y colonias más periféricas del centro. Los purépechas se han instalado mayoritariamente en los municipios de Zapopan, Guadalajara y Tlaquepaque, en este último en diversas colonias periféricas caracterizadas por altos índices de marginación y pobreza. En el mismo municipio, los purépechas comparten el espacio urbano con otros inmigrantes indígenas: otomíes, nahuas, mixtecos, mazahuas, huastecos, huicholes y zapotecos, entre los más numerosos (Bayona, 2006; INEGI, 2005; Martínez-Casas, 2007). Muchos de estos grupos étnicos acuden a vivir en las mismas calles, cerca de paisanos o parientes, y se forman así zonas exclusivas de residentes indígenas, con casas edificadas unas al lado de las otras, que se identifican más por la comunidad de donde provienen que por la etnia a la que pertenecen (Ver cuadros 1,2 y 3 ).

Estos espacios urbanos a los que acceden los inmigrantes suelen estar situados en los límites de la urbanidad, caracterizados por la falta de la gran mayoría de servicios urbanos a los que la ciudad, de por sí, parece incluir en su propia definición. Se caracterizan por ser lugares que contrastan con las comodidades que existen en otras partes de la ciudad; zonas mal urbanizadas, asentamientos irregulares, pocos servicios urbanos e inseguridad. Son las zonas de la marginación urbana que sobreviven a espaldas de la otra ciudad más privilegiada, que refleja las desigualdades sociales y que se convierten en los lugares de residencia para una población con escasos recursos sin posibilidad de traslado. Allí conviven los sectores populares, caracterizados por la marginalidad y la pobreza urbana asociadas a la diferencia de acceso de recursos económicos y sociales dentro de un competitivo mundo urbano. La marginalidad que reproduce la pobreza se manifiesta entre las personas que tienen escasa capacitación laboral para conseguir empleos remunerados, poseen un bajo nivel de escolaridad, se desempeñan en la escala más baja con salarios inestables y en condiciones laborales precarias, lo que provoca alta pobreza y una supervivencia extremadamente precaria en el mundo urbano (González de la Rocha, 1986; Lomnitz, 1975).5

Los indígenas se localizan en estos espacios marginales de residencia, y automáticamente se sitúan entre las capas más marginales de la población urbana. Pero, además de su condición marginal, la procedencia indígena se convierte en un obstáculo para que entren en algunos espacios socioeconómicos periféricos. En los lugares de residencia aparece la primera exclusión social a la que son objeto y, a pesar de convivir con nuevos y antiguos habitantes, mestizos e indígenas, y compartir carencias, pobreza y exclusión urbana, su aceptación en la colonia va desde el que demuestra ser indígena y es rechazado abiertamente, hasta el que lo oculta y siempre es sospechoso de su origen étnico. Además, las diferencias étnicas dificultan en muchos casos las relaciones de los inmigrantes con las instituciones gubernamentales: en el difícil acceso que tienen a mejores niveles de educación, en la atención a la salud, en la exclusión en otros ámbitos de ocio públicos y urbanos, e incluso se enfrentan a calificativos discriminatorios como el de "indios" o "inditos", en contraposición a los habitantes "mestizos" que se consideran los antiguos residentes de la periferia, en una ciudad que siempre se ha caracterizado por su ascendencia blanca, católica y conservadora (MartínezCasas, 2007; Oehmichen, 2001). 
Los inmigrantes comparten de igual manera el difícil acceso al campo laboral urbano, debido no sólo a su procedencia, sino también a las desventajas que tienen por su escasa capacitación en trabajos urbanos y por la falta de redes y los contactos eficaces que permiten entrar a trabajar en la ciudad. La atracción que tiene la capital del estado de Jalisco para la población inmigrante se debe al crecimiento industrial, comercial y de servicios, que ofrece una amplia gama de posibilidades laborales. Su desarrollo comercial la ha convertido en un centro de abastos importante para todo el estado de Jalisco, en donde la economía formal y la informal se encuentran combinadas en la mayor parte de las empresas, fábricas, talleres, y también en la práctica del comercio ambulante (De la Peña, 1993, 2000; Escobar, 1986; Palacios, 1990). ${ }^{6}$

Los indígenas que habitan en ZMG, como ya se comentó, suelen acceder a trabajos mal pagados, eventuales e inestables, dentro de la precaria economía informal, por lo que han establecido diversas estrategias de organización del trabajo en la que algunos involucran a todo el núcleo familiar en un mismo oficio, mientras otros dividen trabajos específicos para hombres y para mujeres. Los éxitos o fracasos de cada grupo dependen de la organización familiar y grupal, así como del trabajo existente y de acceso en el medio urbano. En consecuencia, los indígenas suelen aparecen en trabajos asociados con la fuerza física, para los hombres: fábricas, albañilería, carpintería, jardinería, cargadores o estibadores en los mercados y otros oficios manuales; mientras las mujeres trabajan en actividades relacionadas con el hogar: servicio doméstico, lavado de ropa, o venden tortillas y otros alimentos por las calles.

Frente al excluyente panorama laboral, de pobreza y marginación social, uno de los mecanismos más utilizados por los inmigrantes indígenas es la consolidación del grupo familiar corporativo, con la participación laboral de todos los miembros, unido al fortalecimiento de redes de parientes y paisanos, que se ayudan entre ellos para encontrar trabajos y apoyarse económicamente. En ZMG, encontramos grupos de indígenas en diversos campos laborales. Entre los más visibles, aparecen las mujeres mixtecas que trabajan como empleadas domésticas, o en la venta ambulante de artesanías, comida o mercancía barata que consiguen en alguna tienda de mayoreo; mientras los hombres encuentran trabajos esporádicos, en fábricas y algún trabajo manual, a la vez que forman bandas musicales que son contratadas para eventos festivos en los alrededores del núcleo urbano. ${ }^{7}$ Algunos purépechas son peones en la construcción, otros fabrican muebles de madera o venden tierra para macetas, y se colocan en plazas, calles transitadas o van de puerta en puerta; mientras que los purépechas que se dedican a la mercancía de plástico han encontrado espacios reglamentados de venta en el comercio, conocidos como tianguis. De igual forma, los nahuas del estado de Hidalgo aparecen en la construcción y sus mujeres en el servicio doméstico, mientras los nahuas que proceden de Guerrero trabajan como taqueros o vendedores de artesanías y otros objetos de "ocasión" en cruces y avenidas importantes.

El comercio ambulante es una de las salidas más recurrentes que tienen los indígenas para subsistir en la ciudad, porque es de fácil acceso y no requiere tanta preparación comootros trabajos. En el negocio de la venta hay huicholes, nahuas, otomís, purépechas, mixtecos, zapotecos y tsotsiles, ${ }^{8}$ entre los más numerosos, que venden todo tipo de productos elaborados y de ocasión: artesanías, palmas, muebles, tierra, muñecas de trapo, ropa, objetos de plástico, de fantasía y cosméticos, frituras, papas y otros comestibles. Acuden a diferentes mercados o tianguis, o realizan una venta ambulante alrededor de centros comerciales importantes, o en vías centrales de la zona metropolitana, como el centro histórico de Guadalajara, en las calles que rodean el Teatro Degollado y la Plaza Tapatía, y por las calles turísticas de San Pedro Tlaquepaque, en el núcleo de Zapopan e incluso en Tonalá en los días que se celebra 
el mercado de artesanías (Bayona, 2009; Martínez-Casas, 2000, 2007).

Los purépechas a los que hace referencia este trabajo se han especializado en la venta de mercancías de plástico y otros objetos de bajo costo en tianguis periféricos, con alta demanda entre el sector popular. Cada grupo doméstico tiene más de un punto de venta para conseguir mayores beneficios, y se ha establecido una inserción laboral con base en complejas divisiones de género y generación en la que algunos miembros familiares tienen más peso y poder de decisión que otros. La inserción en la ciudad ha requerido además fortalecer una serie de redes corporativas, con la participación compacta entre familiares, parientes y paisanos, para mantener con éxito el nicho laboral. Los purepéchas así se igualan con otros grupos de inmigrantes que desarrollan una especialidad ocupacional y, para ello, utilizan una serie de instituciones informales alrededor de la captura del nicho laboral: relaciones primarias basadas en el parentesco, liderazgos, matrimonio endogámico, normas y creencias, controles sociales y rituales, con el objetivo de controlar los recursos económicos que tienen en la ciudad (Cohen, 2004; Camus, 1998; Oemichen, 2001, entre otros).

La propuesta de que la migración y la inclusión urbana se realizan de manera más grupal que individual nos obliga a profundizar en el entramado de vínculos y el fortalecimiento de una serie de estructuras primarias: familiares, de parentesco y de paisanazgo, que utilizan los inmigrantes para el proceso de inserción en el espacio metropolitano. Entre los purépechas, la utilización de vínculos parentales y paisanales es esencial para entender el complejo entramado de ayudas y favores, como también de normas y obligaciones, que aparecen en el interior del grupo. Aquí se establecen una serie de redes sociales, de apoyo e identificación grupal en la ciudad, que nos permiten también explicar las vinculaciones constantes que se establecen entre el origen y el destino mediante el tránsito continuo de personas y todo tipo de mercancías y recursos. Con el término "red social" hago referencia a este conjunto de relaciones que establecen los inmigrantes y que tiene una serie de funciones solidarias. ${ }^{9}$ La movilización de personas y recursos está estrechamente ligada a la membresía del grupo y al hecho de que los inmigrantes comparten un origen común y una experiencia migratoria. La membresía que otorga el parentesco y el paisanazgo se convierten en los elementos emblemáticos, con mucha más fuerza que la identificación étnica, que implica a la vez una serie de deberes y lealtades para que el inmigrante sea reconocido como miembro integrante del grupo. Para ello, se requiere una serie de participaciones políticas, económicas y rituales que ahora toman un nuevo significado con el efecto de la migración: lealtad y solidaridad, compartir vivencias y dar sentido a los significados y representaciones sociales que se ponen en práctica. Además, se trata de una pertenencia que debe ser demostrada con continuos viajes y participaciones en la localidad de origen para que sea renovada continuamente. Desde esta perspectiva, el sentido de pertenencia involucra una serie de relaciones primarias que incluye prácticas y significados sociales, algunas de las cuales se refuerzan y otras se transforman, en las que se involucra el establecimiento de normas y valores que son necesarios para mantener la identificación del inmigrante en el circuito migratorio.

A este análisis hay que incluirle el enfoque del grupo doméstico que adopta una organización familiar enfocada al trabajo, lo que implica la necesaria participación laboral de todos los miembros para la supervivencia diaria. Aquí se plantea una reorganización familiar encarada al trabajo, que al mismo tiempo que organiza la unidad familiar productiva sufre transformaciones en la ideología que la sustenta. ${ }^{10} \mathrm{La}$ tensión se establece entre las mujeres y su novedoso papel laboral, entre la posible independencia económica de algunos jóvenes, o entre los contactos inevitables y nuevas relaciones que establecen los inmigrantes con otros habitantes urbanos, a los que se une la influencia 
de la vida urbana y citadina que se refleja en las nuevas expectativas entre las mujeres, los jóvenes y menores de edad. En estos contextos migratorios, la familia cumple una serie de funciones primarias y sustituye el papel de algunas instituciones urbanas: socialización y capacitación laboral de los menores, además de ponerse en marcha una serie de obligaciones, lealtades y mecanismo de control y sanción con variaciones sustanciales según género y generaciones. Asimismo, considerar el grupo doméstico como esencial nos permite analizar los recursos ganados y los destinos de los mismos, así como las decisiones que recaen en cada uno de sus miembros.

Aunque el análisis del grupo familiar y doméstico es la base para entender la organización e inserción laboral, las redes parentales resultan cruciales en el negocio de la venta, no sólo para empezar sino también para conseguir productos y lugares estratégicos, además de ofrecer apoyos en otros ámbitos de convivencia social. En este contexto, el parentesco es una extensión de la familia necesario para comprender las redes de uso en la ciudad. Entre los purépechas, el parentesco comprende una red amplia de parientes lineales: ascendentes, descendientes y colaterales, a los que se añade el parentesco ritual de compadres, ahijados y padrinos. Pero en el proceso migratorio surgen una serie de novedosos arreglos y reacomodos familiares en donde se resignifican tanto los lazos familiares como los vínculos parentales, se incluye a los que no han migrado y permanecen en el lugar de origen. Por último, el traslado a la ciudad ha provocado la consolidación de varias redes de parientes mucho más poderosas que otras, que a la vez que establecen una identificación común crean diferencias sustanciales y mantienen una jerarquía entre inmigrantes.

En el presente trabajo se define a los inmigrantes purépechas como un grupo corporativo, con fuertes vínculos primarios, que se establecen en un medio urbano y organizan su fuente de ingresos a través del comercio ambulante. La noción de corporativismo resulta aquí útil para analizar la forma en que algunos grupos construyen fronteras limitadas de intereses económicos y sociales a partir de una solidaridad interna. Eric Wolf (1999) planteaba que se trata de estructuras suplementarias, paralelas o totalmente marginales, que aparecen en las sociedades complejas, entre las que se encuentran las relaciones de parentesco, de amistad y padrinazgo, que conviven al mismo tiempo que otras estructuras institucionales. Algunas de estas estructuras se convierten en una clara competencia con el poder estatal o lo inflingen para contrarrestar tensiones, mientras otras se adhieren o cumplen funciones paralelas. Para el autor, las unidades de parentesco de tipo corporativo son grupos que se forman a través de vínculos parentales y que controlan una serie de recursos que requieren una coalición para mantener su patrimonio intacto. Los grupos corporativos de parentesco se caracterizan porque sus miembros comparten objetivos comunes y controlan una serie de recursos económicos necesarios para su reproducción. En este sentido, el grupo corporativo utiliza una serie de vínculos primarios, a la vez que tiene reglas claras de funcionamiento y una estructura interna capaz de regular las relaciones entre los miembros mediante la asignación de atribuciones, derechos y obligaciones, a cada uno de ellos, de acuerdo con la posición que ocupan en la estructura. Además, se requieren otros mecanismos de coalición paralelos para restringir el número de miembros en el grupo, como las alianzas matrimoniales y la transmisión de la herencia que conforman corporaciones con fronteras limitadas y de difícil acceso.

Los purépechas son un grupo corporativo que establece y utiliza las redes primarias tanto en el ámbito privado como en el público. Los inmigrantes coexisten en la ciudad con otras estructuras institucionales y organizan el espacio de trabajo y residencia sin una separación clara entre ambos ámbitos. Los tianguis se convierten en el mayor espacio de convivencia de los purépechas en donde trabajan, invierten dinero y conviven con otros inmigrantes. Entre la periferia 
urbana y el lugar natal, aparecen otros microespacios que hacen referencia a aspectos comunes del grupo: las residencias, el centro de la ciudad y, por supuesto, la comunidad de Pamatácuaro, a la que acuden frecuentemente por su cercanía con la ciudad. La idea central en delimitar todas estas áreas en este trabajo radica en que, a pesar de conseguir recursos y sobrevivir de manera grupal en el ámbito metropolitano, los indígenas permanecen enclavados en los espacios urbanos que son reflejo de las desigualdades sociales. Su movilidad social y urbana es escasa y ello se aprecia en el ámbito escolar, en donde la mayoría de los jóvenes han tenido que abandonar la escuela para incorporarse al trabajo comercial, y en la apuesta de los padres para que sus hijos sigan en el negocio y no pierdan los lazos natales. Se crean fronteras hacia dentro y también hacia fuera, porque a la vez que se mantienen una serie de vínculos y el contacto de origen, en la vida urbana el encapsulamiento es mayor, y la convivencia con otros sectores es prácticamente nula. No obstante, lo que veremos es la consolidación de ciertas estrategias económicas y sociales que constituyen mecanismos adecuados para la supervivencia grupal que, aunque enfocado en un contexto marginal, demuestran la capacidad que tiene el colectivo para generar recursos y crear redes sin tener que acoplarse a los ritmos y ciclos laborares que el mundo global impone.

\section{Los inicios y la consolidación del negocio comercial}

La trayectoria laboral de los inmigrantes purépechas empieza alrededor de la década de los ochenta, cuando unas cuantas familias procedentes de Pamatácuaro llegaron al centro histórico del municipio de Guadalajara para probar suerte en el comercio ambulante. El centro de la ciudad posee una gran actividad comercial, sobre todo alrededor del mercado de San Juan de Dios y por las calles Gigantes y Obregón, con tiendas mayoristas y minoristas que abastecen de productos a la gran mayoría de comerciantes ambulantes. En la actualidad, se ha convertido en un lugar estratégico de abastecimiento al que acude todo tipo de vendedores para comprar mercancía barata y tomar el primer contacto con el negocio de la venta. En los primeros años, algunos de primeros inmigrantes purépechas empezaron por rentar cuartos económicos para dormir en vecindades alrededor de las principales calles del centro, y a conseguir trabajos esporádicos; los hombres en oficios manuales y las mujeres en tareas domésticas. Pero otros purépechas empezaron a incursionar en el comercio, y se dedicaron a la venta ambulante de mercancía barata que compraban en alguna tienda mayorista y se trasladaban a diferentes mercados ambulantes, o combinaron la venta ambulante en la ciudad con los mercados o ferias alrededor del núcleo urbano Unos más acudían de puerta en puerta para ofrecer objetos domésticos que transportaban desde Pamatácuaro, como ollas, piezas de madera y otros utensilios de cocina. Entre unas y otras estrategias, poco a poco los inmigrantes fueron teniendo los suficientes beneficios para invertir en más mercancía y convertirse en comerciantes urbanos. Algunos, incluso, llegaron a abrir tiendas de mayoreo en el centro de la ciudad, mientras la gran mayoría se fue especializando en la venta de menudeo en tianguis periféricos con diferentes rutas de venta, al mismo tiempo que renovaban la mercancía hacia productos de consumo urbano. Se estableció así una red de comerciantes pamatacuarenses en la que algunos se dedicaban al mayoreo y la gran mayoría al menudeo, con un organización comercial interna basada en préstamos, ayudas e inversiones, que permitió la llegada de más paisanos que se atrevieron a migrar para entrar en la red comercial, fortalecida y consolidada a medida que fueron pasando los años.

Las primeras décadas de este proceso migratorio fueron decisivas para la captura del nicho laboral comercial, y para formar una red corporativa que se apoyaba en el negocio. En años posteriores, los purépechas comerciantes se trasladaron a vivir a 
otras zonas alejadas del centro, en el municipio de Tlaquepaque, donde consiguieron puestos de venta en los tianguis de colonias populares alrededor de todo el municipio, construyeron casas de propiedad, y formaron pequeños enclaves purépechas organizados a través de lazos tanto parentales como paisanales. En la actualidad, forman un grupo organizado de parientes y paisanos que ha conseguido con "el comercio en Tianguis" y con la venta al mayoreo un nicho laboral exitoso.

El proceso migratorio continúa, año tras año llegan más inmigrantes a la ciudad para probar suerte como sus antecesores. Este proceso tiene una serie de características que lo hace singular: desde sus principios se caracterizó por ser una migración familiar, en la que viajaban padres e hijos para empezar una nueva vida en la ciudad; actualmente llegan otros parientes y paisanos que se instalan en las residencias familiares nucleares. La inserción laboral también es familiar, y trabajan en el comercio la pareja e hijos como un grupo corporativo y familiar que se organiza según divisiones de género y generacionales; esta inserción en el comercio es exitosa y posibilita no sólo sobrevivir diariamente, sino además conseguir las suficientes ganancias para invertir en nuevas mercancías, como también gastar en fiestas particulares y celebraciones importantes en la comunidad de origen; por último, a pesar de que cada grupo doméstico sobrevive con los recursos que consiguen de sus ventas, los apoyos parentales y paisanales se tornan esenciales para empezar y continuar en el negocio comercial. Dichas redes permiten que entre unos y otros se ayuden en la venta y a buscar productos baratos y lugares estratégicos, se presten dinero y vendan mercancía más barata a quienes empiezan en la actividad comercial, se cedan mercancía y puestos en caso que el vendedor esté ausente, informen sobre puestos vacantes, $u$ ofrecen oportunidades de convertir a otros parientes en asistentes y ayudantes en la venta. Las redes comerciales incluyen también comprar mercancía a mejor precio en tiendas mayoristas de otros paisanos o, por ejemplo, organizar viajes a la capital mexicana en fechas señaladas para conseguir mercancía novedosa.

Actualmente, se aventuran a la ciudad tanto inmigrantes adultos como jóvenes de ambos sexos para entran a esta red comercial consolidada que tiene en su interior diferencias sustanciales entre los que fueron pioneros, los que llevan años y los recién llegados. Los jóvenes de ambos sexos son los nuevos protagonistas de este intenso proceso migratorio, entre ellos, las mujeres que se aventuran a irse solas a la ciudad, sin sus padres, hermanos u otros familiares, pero con los contactos necesarios para ser acogidas en la ciudad. Se producen también casos de jóvenes de ambos sexos que son adoptados por otros paisanos, o por hermanos y otros parientes que se convierten en padrinos y tutores de jóvenes, a los que vigilan atentamente para que no pierdan las normas grupales en contacto con el mundo urbano. Los arreglos domésticos son extensos y complejos y ya no obedecen a las normas que rigen la familia extensa comunitaria. Padres e hijos se juntan en la misma residencia junto a algunos familiares del hombre o la mujer indistintamente: hermanos, primos, tíos, sobrinos y ahijados, y no parientes que requieren ser albergados hasta que puedan independizarse y conseguir una nueva residencia. También se mantiene una comunicación constante de mercancías, dinero e información con los parientes que permanecen en el lugar natal, quienes incluso se trasladan de cuando en cuando a la ciudad para pasar unos días con su familia. No obstante, una de las novedades a tener en cuenta en el ámbito urbano es la creación de residencias neolocales, en donde la pareja, a pesar de albergar durante temporadas o acoger a otros miembros, forma un nuevo hogar, se sostiene con sus propios recursos, y ya no mantiene la residencia obligatoria patrivirilocal de la comunidad de origen, por lo que la mujer, aparentemente, adquiere una mayor autonomía.

En el espacio urbano, la creación de estas redes de apoyo es esencial para la supervivencia, sobre 
todo si llegas de nuevo a la ciudad y no tienes los recursos suficientes para empezar en el negocio del comercio. Las redes se crean y consolidan a través de una identificación comunal y parental, lo que quiere decir que se apoya al nuevo inmigrante por ser de Pama y por pertenecer a una familia determinada. Pero también por el hecho de convertirse en comerciante y seguir la tradición de una especialización laboral que para muchos es heredada desde su tierra y "se lleva en la sangre". El buen comerciante de Pama sabe buscar las ofertas, vender a buen precio y sacar las suficientes ganancias para poder invertir de nuevo. Incluso, se cuentan mitos alrededor de los primeros inmigrantes, los pioneros que, con gran esfuerzo, consiguieron abrir las puertas a sus sucesores por su capacidad de buenos comerciantes. Ellos fueron los que iniciaron el proceso de inserción laboral, y ofrecieron trabajos a paisanos como asistentes en las tiendas mayoristas, a la vez que un aprendizaje estratégico en el mundo comercial urbano.

La estrategia para entrar en el comercio urbano de los pioneros se basó en el sistema de fiado, se convirtieron en intermediarios, desde el origen hasta el destino migratorio, pidiendo todo tipo de objetos domésticos para venderlos a mayor precio en la ciudad y volver a la comunidad para pagar una deuda con la que salían beneficiados. Pero en la ciudad, encontraron un filón de oro en el comercio urbano: en la especialización de productos de plástico, en encontrar locales mayoristas, y en localizar espacios ambulantes de venta. Implicó a la vez consolidar las estructuras primarias y elementales de apoyo e identificación que, a medida que el proceso se fue consolidando, dio como resultado una diferenciación entre parientes que habían tenido más suerte al llegar en un momento propicio de auge comercial, en encontrar lugares de venta exitosos y productos más baratos y vendibles. Actualmente, la huella de los pioneros implicó no sólo conocer e incursionar el espacio de venta de la ciudad, sino también el especializarse en productos urbanos de gran consumo.
La práctica de la organización familiar utilizada por los pioneros, orientada a la participación laboral de la pareja y todos sus hijos, permanece hasta hoy como una de las estructuras más eficaces para conseguir ganancias en el negocio del comercio. La organización para el trabajo implica la completa participación del grupo doméstico, y también la especialización en productos por género y generaciones. Los hombres se han especializado en artículos de plástico y utensilios domésticos como cubos, estropajos, comales, pinzas de la ropa, tazas y vasos de plástico, etcétera., que resultan económicos y fáciles de vender por su alta demanda entre las amas de casa. Algunas mujeres ayudan a sus maridos o tienen puestos paralelos con los mismos productos, mientras atienden y cuidan a sus hijos menores en estos espacios comerciales. Otras vendedoras han encontrado en los objetos de mercería y perfumería un recurso importante para incursionar en la venta de menudeo, que les permite ganar su propio dinero y administrarlo para el hogar y los hijos. Los menores en edad escolar apoyan a sus padres en horarios libres de la escuela; ayudan en las cuentas y en ofrecer productos, y aprenden el oficio de sus padres memorizando precios y viendo tácticas de venta. Los jóvenes venden discos compactos, cintas de música y películas piratas, copias de originales que se consiguen a precios bajos en tiendas mayoristas. Con este tipo de negocio destinado a un consumo juvenil, los adolescentes han conseguido cierta independencia económica, ya que parte de sus ganancias van destinadas a su uso personal, también les a permitido establecer contactos que otros jóvenes no indígenas de la periferia. Muchos de ellos han tenido que sacrificar sus estudios para incorporarse al oficio de comerciantes, no obstante entran en un negocio consolidado de paisanos que les asegura el futuro laboral.

Con esta diversificación de tareas y productos aseguran un ingreso más alto, pero esta organización familiar requiere una serie de apoyos necesarios pare empezar y consolidar el negocio. Las relaciones 
primarias se basan en la confianza y la solidaridad, y es aquí donde aparecen múltiples redes de inmigrantes que crean subgrupos, con mayor o menor capital social, con obligaciones y lealtades, y con inmigrantes que se incorporan a la red básicamente por parentesco real o ritual. Así, es común y obligatorio ayudar al recién llegado, ofrecer residencia y comida, prestarle dinero en malos momentos, o cuidar a los niños o enfermos de un pariente necesitado. La norma ideal es que entre parientes y paisanos no se engaña, pero lo cierto es que no todos se ayudan porque se requiere tener ciertos vínculos “de sangre” para tener más éxito.

Desde la primera década migratoria, las familias extendieron la parentela y se crearon nuevos lazos a través de alianzas matrimoniales y compadrazgos. Hoy hay parientes con mayor poder adquisitivo, con mejores contactos y prestigio social dentro del grupo. Es común encontrarlos en la organización de fiestas y eventos importantes en la ciudad, son los que tienen las casas más grandes que, además, se convierten en centros importantes de reunión, y asumen la recolección del dinero necesario para los cargos religiosos en el lugar natal, que requieren una gran inversión en comidas y celebraciones asociadas con el cargo. Su poder se extiende al establecimiento de una serie de normas que provienen del lugar natal, y se legitima por medio de dinero, de inversión y participación, pero también de información, porque las noticias corren de un lado a otro y las prácticas transgresoras se sancionan tanto en la ciudad como en la comunidad de origen.

La mayor parte de la mercancía que venden los purépechas comerciantes se consigue en las tiendas al mayoreo en el centro histórico de Guadalajara. Los paisanos que poseen tiendas mayoristas ofrecen productos baratos, que ellos han conseguido todavía a un precio menor de coste, y realizan negocios rentables por la cuantía de artículos que cada minorista necesita renovar continuamente. De cara al negocio comercial, no existen favoritismos hacia los paisanos, pero si se establece el negocio bajo otros parámetros; se fían productos hasta que los vendedores puedan pagarlos, crean sucursales mayoristas con parientes, abren nuevos puestos en los tianguis periféricos a cargo de algún purépecha de confianza, o permiten que otros comerciantes dejen sus productos fiados para que se vendan a mejor precio que en los mercados ambulantes. Los mayoristas se han convertido en intermediarios de una cadena comercial que tiene mayores beneficios si te encuentras entre los eslabones superiores, y son un modelo a seguir para muchos de sus paisanos.

A excepción de los mayoristas que viven en el centro histórico de Guadalajara, los demás comerciantes acuden al centro de la ciudad únicamente para comprar mercancía, y el resto de la semana permanecen en una colonia de residencia caracterizada por una larga historia de marginación y abandono político y económico.

Las colonias de los Barrios de Las Juntas y Las Juntitas se construyeron de manera irregular a partir de la década de los ochenta sin los permisos legales adecuados, en donde a pesar de poseer los servicios básicos de agua y electricidad, la mayoría de las calles están sin asfaltar, no hay alumbrado por las noches y la basura se acumula en las esquinas hasta la recogida semanal. Las calles van creciendo a medida que se edifican nuevas residencias, algunas en calles sin salida, otras en las faldas de las montañas, y el drenaje está tan deficiente que los olores de aguas negras penetran en dichas residencias, sobre todo cuando se concentra en la época de lluvias. La zona, además, es especialmente peligrosa y dañina para la salud porque está próxima a la carretera del periférico y a la vía del tren, y alberga industrias químicas, una fábrica de cemento y otra de cal, y vertederos de basura, algunos rellenados y con residencias, y otros en donde se tiraron desechos orgánicos, también químicos y otros productos que continuamente emanan gas tóxico.

Los purépechas poseen una visión acotada de la zona metropolitana al residir y trabajar en estas zonas al margen de la urbanidad, aunque en algunas ocasiones se 
trasladan a otras partes de la ciudad cuando hay fiestas y mercados importantes, como en la Peregrinación de la Virgen de Zapopan el 12 de octubre, en donde han conseguido establecer puestos de venta rentables. Con los puestos que ahora tienen les basta para ganar dinero, ahorrar lo necesario y el resto invertirlo en objetos materiales y gastos comunitario. Los escasos contactos que mantienen con la sociedad urbana son reflejo del encapsulamiento del grupo y a la vez del rechazo y discriminación que padecen. En la misma colonia o alrededores, los niños acuden a las escuelas, aunque siempre ocultando su origen, pero los padres prefieren reforzar una socialización laboral con el fin de que se conviertan en futuros comerciantes. Utilizan la lengua purépecha sólo en los ámbitos familiares y comunales, y eligen además no acudir a los centros médicos por el mal trato recibido, por lo que optan por acudir a las sanadoras que viven también en la ciudad y tiene los remedios adecuados para sus males. Tampoco establecen relaciones cordiales con los vecinos del mismo barrio, ni reciben apoyos institucionales, aunque hay quien prefiere negociar de manera individual para conseguir algún beneficio económico y social con alguna institución. En el ámbito ritual y religioso es probablemente en donde aparecen las mayores diferencias con la sociedad urbana y periférica, y no suelen participar en las fiestas barriales ni tampoco acuden a la iglesia los domingos, porque ellos dicen que los días festivos son de trabajo, así prefieren celebrar rituales propios y hacer reuniones para "hablar de la palabra de Dios" en casa de algún pariente. Además, las celebraciones importantes acontecen en Pamatácuaro, que son los días de congregación comunal, e implican a la vez una ruptura con el acelerado ritmo laboral que mantienen en la ciudad.

\section{La convivencia entre buenos comerciantes}

En la Zona Metropolitana de Guadalajara, la actividad comercial representa un medio de vida que utiliza un gran sector de la población que trabaja tanto en mercados fijos y tiene puestos de venta que cumplen con los requisitos de un trabajo formal, como en la venta ambulante e informal. Entre el abasto y la venta de productos, se establecen diferentes cadenas comerciales formales e informales, entre mayoristas, agentes comerciales, intermediarios, y comerciantes de gran y pequeña escala, con luchas internas entre diferentes vendedores e intermediarios que conforman un espacio comercial altamente competitivo (Padilla y Niembro, 1986; Oehmichen, 2001). La venta en los tianguis representa casi el último eslabón de esta cadena comercial que se abastece del sector comercial de gran escala, y entra dentro de la categoría informal al no estar regulada por la legislación estatal, además de que los precios de las mercancías y la calidad de los mismos no se hallan regulados por las normas de la actividad comercial.

Los tianguis periféricos cumplen la función de abastecer a un gran sector de la población que vive alejada del centro y requiere consumir productos comestibles e industriales. En el municipio de Tlaquepaque se celebran 48 tianguis a lo largo de la semana, con jornadas diarias de ocho de la mañana hasta las cuatro de la tarde de lunes a viernes, a las que se añaden los fines de semana y los días de festividades importantes con un horario ampliado hasta la noche. Los tiangueros acuden a un sitio público designado por el ayuntamiento y pagan una cuota por el espacio que ocupan para la venta, que varía según el tamaño del lugar y el mercado ambulante. La venta va dirigida a un sector de la población que acostumbra a efectuar la comprar diaria, especialmente amas de casas que requieren comprar comida y algo secundario para el hogar o para sus familiares, y otros compradores que siempre se llevan algo no tan necesario para el sustento diario. Los purépechas especializados en objetos de plástico, discos compactos, objetos fantasía y otros productos de escaso valor económico, obtienen grandes beneficios con sus ventas, porque cada día acuden a un 
tianguis diferente, poseen grandes puestos de venta, e incorporan constantemente nuevas mercancías. Los fines de semana son especialmente rentables porque hay familias enteras que acuden a pasear y comprar en los mercados, además de otros días festivos, como por ejemplo el Día de Muertos o en Navidad, que es cuando se puede doblar la venta.

En el tianguis se vislumbra una jerarquía de los paisanos conseguida con el paso del tiempo: hay comerciantes con puestos de venta más estratégicos conseguidos a través de años de conquista y competencia con otros vendedores. Otros, sobre todo los recién llegados y algunos vendedores sin redes eficaces, se conforman con los puestos libres que quedan una vez se reparten todos los lugares. Hay paisanos además que tienen varios puestos, con todos los miembros familiares funcionando, mientras otros tienen sólo uno o recorren los pasillos vendiendo la mercancía de otros comerciantes. La red comercial funciona en su interior basada en lealtades, obligaciones, pero sobre todo debido a años de experiencia en un contexto comercial, con reglas de operación complejas, con algunos favoritismos hacia mercaderes locales, y con una amplia gama de vendedores, intermediarios, competencias y mercancías. Los purépechas no han establecido ninguna relación vertical con líderes, familias poderosas, en el terreno comercial o de tipo clientelar con otros comerciantes no indígenas. Quienes llevan años en el negocio establecen relaciones horizontales y de confianza con otros vendedores creados en el ámbito comercial cotidiano y común que no se extiende a otros ámbitos. Sus propias redes sustituyen las de otras instituciones, y prefieren no mantener relaciones cordiales más allá del trato comercial y el que se establece con los posibles compradores.

Pero el tianguis no es sólo un medio de vida accesible, también se convierte en el lugar adecuado para efectuar todo tipo de relaciones familiares y de convivencia con otros inmigrantes con los que coinciden en los mismos espacios de venta. Se estructura la jornada diaria alrededor de la actividad comercial, y las parejas y sus hijos pasan muchas horas juntos, mientras se pasea y conversa con otros paisanos. Es aquí donde se fortalecen relaciones, se proponen negocios y otros tratos comerciales, se comentan noticias y se sancionan conductas, por lo que el tianguis se convierte en un importante espacio de control social. Se explican situaciones de familias necesitadas que pasan un mal momento económico, de noticias novedosas sobre la localidad de origen, de mujeres que acaban de enviudar, de fallecimientos, enfermedades, de remedios caseros, de entierros y otras desgracias, pero también aparecen chismes sobre disputas conyugales, embarazos no deseados y en soltería, sobre los vicios urbanos que adquieren los hombres y aún peor entre las mujeres, y de quién no ha participado con dinero en cargos y rituales religiosos. Además, las noticias aparecen mucho más acentuadas en el caso de las mujeres y jóvenes, que han accedido con protagonismo al ámbito público, porque el control social va estrechamente relacionado con lo que se espera de cada género y generación.

En la ciudad, una de las mayores actividades públicas de las mujeres es la comercialización de productos en los tianguis, que implica la venta pero también el trasladarse a las centrales de abastos para reponer la mercancía. Pero para las mujeres los tianguis representan también una extensión de las tareas familiares y domésticas que ahora se realizan en un ámbito público bajo la supervisión de otros paisanos. Se convierten en comerciantes, pero no dejan de ser amas de casa y madres de sus hijos. La socialización familiar y el trabajo de los niños se establece en estos espacios de venta, y son las mujeres las que alimentan y educan a sus hijos más pequeños, supervisan las tareas escolares, les enseñan a comer y a hablar purépecha y español, les permiten jugar o les riñen si no se portan bien. Alrededor de los ocho o diez años, los niños se incorporan al negocio de la venta con mayores responsabilidades: dar cambio y regatear por su propia cuenta y atender el puesto si alguien se ausenta. De las niñas también se 
espera que aprendan los deberes asociados al hogary, al finalizar la jornada de venta, deben ayudar a sus madres en las tareas de la casa. La temprana integración de los jóvenes de ambos sexos al mercado laboral también tiene diferencias sustanciales de género. En esta etapa en que la venta ya es algo aprendido, los varones se independizan y montan sus propios puestos de venta, siempre con la ayuda de algún pariente que les ha ofrecido mercancía o dinero para empezar en el negocio. Al contrario, las mujeres jóvenes deben conformarse con ayudar a algún familiar o pariente cercano y no reciben el mismo apoyo para incursionar individualmente en el comercio, por lo que pocas se atreven a entrar solas en el negocio y son más criticadas por sus fracasos. Además, las mujeres si se casan pronto pasan prácticamente de ser niñas a madres y esposas, y si participan en la venta de manera individual es porque tienen puestos vigilados por sus progenitores, o porque ya forman parte de una familia y son responsables de la manutención económica tanto como los hombres.

Los tianguis también son el lugar propicio para entablar los primeros contactos entre jóvenes de ambos sexos que quieran consumar una relación conyugal. En Pamatácuaro, los matrimonios se realizan en la etapa adolescente, a partir de los catorce años, en la que familiares y parientes acuerdan el enlace y las fechas de celebración. En cambio en la ciudad muchas alianzas se posponen, en parte porque para los hombres jóvenes la soltería en la ciudad es algo que se valora ya que permite cierta libertad para pasear y conocer un ámbito urbano fuera de las coordenadas grupales. Por eso ahora algunos jóvenes prefieren cortejar a las mujeres en fiestas particulares o en lugares anónimos urbanos, fuera del control de los tianguis y de los chismes que pueden llegar a oídos de sus progenitores. Algunos efectúan el "rapto de la novia" como una fuga concertada entre una pareja joven que agiliza el proceso de unión conyugal sin tanto gasto ni intromisión de parientes. Otros, al contrario, van a buscar a sus futuras mujeres a Pamatácuaro, con arreglos en presencia de ambas familias residentes en ambos espacios migratorios, y con un estricto control en la etapa del noviazgo por parte de parientes o de otros inmigrantes que asumen el papel de sustitutos familiares en la ciudad.

De igual forma ocurre entre las mujeres solteras, que ahora cuestionan normas asociadas con su antiguo rol de esposas y amas de casas y quieren acceder a otras relaciones y espacios urbanos. Pero sus relaciones no son muy extensas y se reducen a la convivencia ahora fortalecida entre paisanas, en los espacios de venta y en núcleos domésticos. Así, a la vez que hablan de nuevas expectativas laborales y de parejas adecuadas, unas buscan posibles maridos entre una opción limitada, otras esperan a ser escogidas, mientras algunas optan por la soltería para no perder las escasas libertades conseguidas en el ámbito público. Por otro lado, la endogamia provoca que la mayoría de las mujeres casadas mantengan contactos con la localidad y con los vínculos familiares asociados a una filiación y autoridad masculina. Pero hay quienes piensan que en la ciudad los papeles entre hombres y mujeres se han alterado y ahora ellas pueden organizar su propio núcleo familiar y contribuir con el sustento. No obstante, para los hombres el ámbito público de las mujeres comporta cierto riesgo y posible alteración de normas, y refuerzan su autoridad mediante la participación de otros miembros familiares, como hermanos y tíos, que actúan como sustitutos del control que ejercían los suegros en la localidad de origen. Además, para el hombre, el matrimonio no sólo posibilita formar una familia con la esperada descendencia, sino también comporta prestigio como adulto y responsabilidad en la manutención económica y normativa. Y ahora, el moderado éxito comercial en la ciudad permite la subsistencia y también la reproducción familiar, aunque para ello sea necesaria la participación laboral de la mujer en la esfera pública.

Los tianguis también se han convertido en el lugar propicio para aprender el negocio de la venta, a través de los más experimentados que enseñan a 
los novatos o recién llegados sin distinción de género ni edad. Se requiere un aprendizaje en una serie de tácticas para poder integrarse a la red comercial, y se ha establecido una especie de rito de paso entre los nuevos inmigrantes que tienen que demostrar que son buenos negociantes. Los primeros préstamos, para empezar e independizarse en el negocio, se consiguen entre parientes, pero las ganancias deben ser lo suficientemente rentables para poder seguir por sí mismos en el comercio. Para ello, el buen comerciante empieza por saber escoger una mercancía barata y fácil de vender, y también por negociar tianguis y espacios de venta estratégicos. Hay que sacar el mayor beneficio posible, lo que implica trabajar diariamente y no tener prácticamente ninguna hora de descanso. El buen comerciante debe también saber administrar sus ganancias para poder comprar nueva mercancía, que se realiza una vez a la semana o cada quince días. Además, los puestos de venta deben siempre estar abarrotados de mercancía para atraer a más compradores, de esta forma el reemplazo se convierte en necesario para que el negocio sea rentable. Lo que se gana se invierte de nuevo, y lo que sobra se ahorra para gastos extras y comunitarios. Los gastos urbanos deben ser los necesarios, sin excederse demasiado y con lo suficiente para sobrevivir diariamente, y sin tener que recurrir de nuevo a préstamos con riesgo de desequilibrar la económico familiar. Ello implica, entre otras estrategias, comer en los tianguis, comprar la ropa y los alimentos necesarios en puestos económicos, y conservar dinero para otros gastos de la casa: gas, medicamentos, coche y gastos de los niños y de la escuela. En cambio, los gastos comunitarios son todo lo contrario, porque se invierte en la participación comunitaria, en objetos urbanos y en la construcción de edificios particulares y comunales que requieren una gran inversión.

La capacidad individual de cada vendedor contrasta con la organización familiar que se establece, en donde la pareja y los hijos deben trabajar y reunir dinero conjuntamente, aunque los padres son siempre los que aportan cantidades superiores y asumen mayores gastos. El trabajo femenino es uno de los soportes fundamentales para sacar beneficios y para continuare invertir en más mercancía. Aquí se valora la capacidad del comerciante tanto si es hombre como si es mujer, pero sí se establecen metas diferentes según género y generación. De esta manera, mientras las mujeres casadas y solteras se encargan de los gastos cotidianos y domésticos, los hombres casados deciden las grandes inversiones en el ámbito privado y público, porque se requiere financiar las festividades y mantener las relaciones sociales tanto en la ciudad como en la localidad; mientras los solteros, como hemos visto, prefieren invertir en una nueva vida en la ciudad. De hecho, el comercio que produce beneficios sustanciales ahora también se demuestra con inversiones que ofrecen cierto prestigio en la ciudad: nuevos electrodomésticos, como refrigeradores y lavadoras, equipos de música y televisores, que aparecen en la mayoría de las casas, lo que refleja el nivel adquisitivo familiar que adquiere nuevos objetos de consumo urbano. Las residencias poseen grandes cocheras para guardar las camionetas que sirven para transportar la mercancía, también para acudir frecuentemente al lugar natal, por lo que se invierte en una considerable suma en la compra y mantenimiento del vehículo. Tampoco faltan las imágenes de santos y vírgenes, entre otros la imagen del Niño Dios, que incluye un ritual que empieza desde la comunidad de origen y que en la ciudad implica una serie de costosas celebraciones a las que acuden algunos paisanos. Otra imagen importante es la Virgen de la Inmaculada Concepción de Cocucho, que procede de una comunidad cercana de Pamatácuaro y que se ha convertido en uno de los rituales urbanos de congregación paisanal más importantes. Se considera tan milagrosa que todos desean tenerla en casa, pero para poderla albergar se requiere esperar cerca de un año, mientras pasa de casa en casa, lo que permite a la vez preparar los ingresos necesarios para la 
congregación de inmigrantes que, incluso, se trasladan desde otras colonias cercanas para llegar a la ceremonia.

Por eso, el dinero no sólo sirve para ostentar en objetos materiales, sino además para afianzar relaciones sociales; permite preservar la solidaridad entre parientes y paisanos, fortalece una reputación familiar que automáticamente heredan los hijos, ofrece la posibilidad de celebrar y organizar fiestas, y constituye un recurso para invertir en otros negocios y prestar a otros paisanos. Las ganancias de la venta se pueden invertir también en prestigio social comunitario, que siempre se halla vinculado con las inversiones que se realizan en la localidad natal relacionadas con regalos y obsequios para sus parientes y cargos de rituales religiosos, pero también en la celebración de otros rituales paralelos como bodas, comuniones y quince años, que ahora requieren un mayor gasto, así como para préstamos y deudas que se pagan en años.

Se vive en la ciudad para ganar dinero y poderlo invertirlo en la comunidad porque, al fin y al cabo, la mayoría desea retirarse algún día a su lugar natal, y para ello también invierte en la compra de terrenos y construye nuevas casas con el objetivo de no perder ese referente rural. Pero a pesar de demostrar que ya se es urbano, hay quien puede invertir más dinero que otros, participa con gastos excesivos en los rituales y demuestra mayor poder a través de las ganancias conseguidas con esfuerzo y trabajo en el comercio urbano. Los rituales $\mathrm{y}$ otras celebraciones permiten congregar a ausentes $\mathrm{y}$ locales, aunque también manifiestan diferencias sociales y económicas asociadas con un proceso migratorio que ha provocado el suficiente beneficio económico como para traspasarlo al ámbito social.

\section{Conclusiones}

En las páginas anteriores he tratado de analizar las estructuras primarias y sus redes de vinculación, con sólidos referentes en la localidad de origen, que utiliza un grupo de inmigrantes para afincarse en el negocio de la venta en la periferia metropolitana. El grupo de inmigrantes ha desarrollado una especificada ocupacional con base en las redes que ha fortalecido a medida que el proceso migratorio ha ido ganando en complejidad y en participación migratoria. Se puede considerar a este grupo de inmigrantes como un caso atípico entre la población indígena de la Zona Metropolitana de Guadalajara, que no sólo ha conseguido consolidar un nicho estable y con relativo éxito, sino también ha formado una compleja organización social para mantenerlo. Ello se demuestra en la red entre mayoristas y minoristas que asegura el éxito de la especialización de productos y espacios de venta, así como en las redes que se han ramificado y ampliado a medida que las familias y los parientes se han extendido en la ciudad. También se vislumbra en los mecanismos de control social que se establecen, mucho más severos para las mujeres que para los hombres, que aseguran la permanencia como un grupo consolidado con intereses comunes.

El contexto de marginación, pobreza y abierta discriminación a la que son objeto los inmigrantes indígenas favorece la consolidación de relaciones de carácter informal, como son las del paisanazgo y parentesco que permiten, además, seguir manteniendo una adscripción comunitaria. Ante el abandono orechazo institucional y las escasas relaciones (que no contactos) con otros habitantes de la zona metropolitana, los purépechas conforman un grupo corporativo, cada vez más hermético y cerrado, que sustituyen las carencias del entorno social y físico en los que viven. Y es que, de alguna forma, el medio hostil urbano les obliga a crear el grupo con marcadas fronteras para mantener un nicho con amplias beneficios, y pareciera que no requieren mantener muchos más contactos más allá de su propia red comercial. Entre todos los ámbitos públicos, el comercial es el de mayor aproximación, que también se engloba en una economía informal urbana, y que para los purépechas es el espacio en donde los ámbitos privados y públicos llegan a confundirse; 
donde se realiza la vida familiar, donde se aprende y se consolida un oficio, y donde también se manifiestan más abiertamente las normas grupales. Ello se aprecia acentuadamente en las normas de comportamiento hacia las mujeres y los jóvenes de ambos sexos, en las que ahora se involucra a los parientes de la ciudad como sustitutos de la autoridad comunal, y en educación de los hijos que corresponde más a la familia que a la escuela, en donde colaboran también otros miembros grupales. La educación relegada al campo del comercio manifiesta otros intereses, porque al fin y al cabo este proceso migratorio no ha comportado aprender conocimientos escolares, sino una serie de habilidades comerciales necesarias para la supervivencia.

El corporativismo encuentra su expresión en relaciones que ofrecen un orden interno que es eficaz para el negocio, aunque también para la reproducción social de las familias, sus parientes y otros miembros de las redes comerciales. El uso de la relación paisanal, y mucho más el parental, desarrolla una serie de mecanismos de lealtad y respeto que se deben unos a otros para asegurar la inserción y la continuidad del negocio. Los inmigrantes se ayudan porque son paisanos, pero mucho más porque el parentesco entre ellos exige una solidaridad y reciprocidad interna. Estudios similares han propuesto que el parentesco en México se convierte en la base para la conformación de grupos urbanos específicos; su uso para la supervivencia cotidiana, la captura de nichos económicos, la creación de empresas o la utilización del parentesco para mantener una elite política entre otros (Lomnitz, 2001; Oehmichen, 2002; Padilla, 1997). Pero entre los purépechas, el parentesco va más allá de las obligaciones y lealtades específicas para convertirse en un principio organizativo que se acopla a una organización comercial. A este tipo de relaciones grupales parentales, Eric Wolf (1999) las denominaba organizaciones comerciales corporativas, que conservan un tipo de relación parental para conseguir un beneficio económico, y que en el caso de los purépechas se vislumbra en la compleja organización para el trabajo establecido en el grupo familiar y doméstico, diferenciada por género y generaciones, así como la normatividad entre parientes enfocada al ámbito comercial. Las obligaciones familiares y parentales se trasladan del ámbito público al privado y viceversa, y en este sentido la familia, a la vez que flexibiliza sus organización con diversos reacomodos residenciales y para acoplarla a los ritmos de trabajo, refuerza la ideología de acuerdo con las normas y valores que sostiene la red de comerciantes.

En la ciudad, los purépechas negocian posiciones dentro de un entramado no exento de diferenciación social, que ahora toma nuevos matices a través del género, la edad, el nivel económico y también social de los inmigrantes. El moderado éxito económico ha comportado diferenciación social dentro del grupo, que ahora se demuestra en ganancias y en inversiones, pero mucho más por antigüedad migratoria y por pertenecer a una red de parientes mucho más fortalecida que otras. Las diversas redes de comerciantes tienen más o menos éxito según los contactos que poseen con las redes de pioneros o de otras parentelas extensas enriquecidas, mientras que el dinero conseguido de la migración y a través del comercio se transforma en la ciudad y en la localidad de origen en bienes materiales valiosos y en recursos sociales. Eric Wolf (1999) ya señalaba cómo los mecanismos de parentesco pueden ampliarse y modificarse para adaptarse a diversos intereses; grupos que restringen los lazos de afinidad y de alianza para limitar su acceso. Su expresión entre los purépechas es la composición de familias con una mayor antigüedad, prestigio, poder y dinero, que conforman subgrupos de parentesco que acceden y limitan la entrada a otros inmigrantes. La restricción a ciertas redes no implica que los mecanismos de control sean menos eficaces, al contrario, pareciera que cuanta más diferenciación se crea, más necesario es reforzar una adscripción al grupo, y se utilizan tanto códigos morales, como 
participación ritual, y una circulación constante de mercancías, dinero e información entre la localidad natal y la colonia periférica urbana.

En este contexto de exaltación de la diferencia, el dinero adquiere otros significados sociales. Por una parte, se involucra en las necesarias relaciones de reciprocidad entre familiares y paisanos, en las ayudas para las inversiones de negocios, en los créditos que se otorgan para poder efectuar fiestas, en los préstamos en caso de necesidad familiar, y también en las ayudas y regalos que ofrecen a sus familiares en la localidad. El dinero es el sustento para una familia: permite sobrevivir diariamente, y también efectuar constantes viajes a la comunidad e invertir en residencias futuras para los inmigrantes. El dinero también se convierte en un mecanismo de la diferenciación de género porque las grandes inversiones no son sólo asuntos de hombres, sino que además involucran a toda una parentela en la que la mujer es reconocida por la filiación masculina a la que pertenece. Pero por otro lado se convierte en un símbolo de un prestigio asociado al éxito del comerciante y se demuestra tanto en la compra de objetos de consumo y obras de construcción, como en la participación comunitaria que en Pamatácuaro se asocia a rituales religiosos y celebraciones paralelas. Desde esta perspectiva, el consumo se está convirtiendo en una demostración de prestigio, a través de gastos sociales y de la compra de ciertos productos que provienen de un mundo más urbano que rural, y que se clasifican como importantes en la conexión de los dos espacios. Pero también en la demostración de un gasto ritual que implica cantidades mucho más elevadas que las que puede sostener una familia de comerciantes, a no ser que involucre a otros comerciantes parientes que automáticamente adquieren un reconocimiento mayor con su participación monetaria. En otras palabras, la inversión en objetos de consumo, regalos, construcciones, fiestas religiosas y otras celebraciones, parecen excesivos si no se traducen en un prestigio social en el mundo urbano y rural, asociado a una mayor capacidad económica entre unos y otros inmigrantes.

La normatividad que se establece entre las relaciones solidarias parece estar entrando en un campo de conflictos que provoca diferencias sustanciales entre unos y otros inmigrantes, y a la vez está también creando tensiones entre las mujeres y los jóvenes de ambos sexos, quienes se han convertido en nuevos protagonistas de un mundo urbano que posibilita otras expectativas fuera de las coordenadas grupales. Las decisiones individuales se supeditan al interés común del grupo: los jóvenes se convierten en comerciantes expertos a edades tempranas, y las mujeres consiguen sustento económico, pero no independencia en otras esferas sociales. La trasgresión no es perdonada, pero los bordes de las fronteras tampoco son tan precisos, por lo que las tensiones futuras pueden derivar en transformaciones de una dialéctica constante entre la norma y la invención. En cualquier caso, actualmente el negocio prospera con base en relaciones, lealtades, solidaridad e intereses comunes, y no existen casi opciones para sobrevivir de manera individual en la ciudad. Prueba de ello son los necesarios préstamos y otras ayudas no económicas que se requieren para salir adelante, los apoyos sociales que integra la red, como también el desprestigio que se adquiere por querer independizarse. El corporativismo aquí entra en contradicción con el interés exclusivamente individualista o familiar que pudieran presentar los comerciantes, aunque los empresarios mayoristas parecen apuntar a esta dirección con sus elevadas transacciones. Son intermediarios con varias opciones por delante: mantener su poder como empresarios locales con normas y valores grupales, o convertirse en comerciantes cosmopolitas y crear nuevas redes comerciales en busca de un beneficio individual, una opción de negocio que bien pueden heredar sus descendientes. En cualquier caso, su huella queda presente en las puertas que han abierto al resto de paisanos en el comercio urbano y en una serie de 
valores asociados, como la solidaridad, el trabajo y el esfuerzo familiar, que actualmente resultan eficaces para la incursión urbana.

\section{Notas}

${ }^{1}$ Para los datos de este artículo, la Zona Metropolitana de Guadalajara (ZMG) incluye los municipios de Guadalajara, Tlaquepaque, Tonalá y Zapopan.

${ }^{2}$ El trabajo de campo se realizó entre 2003 y 2005 con inmigrantes purépechas de la Colonia El Campesino, dentro de un proyecto de investigación más amplio titulado Niños Indígenas en escuelas urbanas: el caso de Jalisco, supervisado por el Dr. Guillermo de la Peña y la Dra. Regina Martínez Casas. El proyecto analizaba la inserción escolar y laboral de los niños indígenas en el ámbito metropolitano. Se contó con el apoyo financiero de Ciesas y la Fundación Ford.

${ }^{3}$ Esta zona se encuentra conformada por las colonias Las Juntas, Nueva Lázaro Cárdenas, Brisas de Chapala, Las Vegas, La Indígena, Las Juntitas, El Tapatío, y pasando la vía de tren, El Campesino, La Micaelita, La Guadalupana, Romita (Salvador Vidrio), El Vergel y Compositores. Tras el periférico se forman las colonias de Las Pintas de Abajo y Las Pintas, Ojo de Agua y Juan de la Barrera. En la colonia El Campesino, se encontraron cerca de 300 miembros purépechas emparentados por parentesco y paisanazgo que se dedicaban a la venta de productos en los tianguis de dichas colonias.

${ }^{4}$ Uno de los problemas que encontramos en la consulta de los datos censales entre la población indígena es su contabilización únicamente por la lengua, lo que puede ocultar una cuantificación exacta de los indígenas que no hablan la lengua o no quieren revelar su procedencia étnica debido a la discriminación que padecen en la ciudad.

${ }^{5}$ Para Lomnitz (1975) y González de la Rocha (1986a), los sectores de escasos recursos combinan una serie de estrategias para hacer frente a su precariedad: ayuda entre parientes, vecinos y amigos, creación de redes de intercambio y de solidaridad, combinación de trabajos formales e informales, y una organización familiar encarada a la inserción laboral de todos los miembros basada en divisiones por género y generaciones. Son estrategias que también utilizan los inmigrantes indígenas, a las que añaden la consolidación de un grupo corporativo con base en identificaciones parentales y paisanales con fronteras sociales muy marcadas.

6 El término informalidad designa todo tipo de actividades laborales que no se hallan reguladas por el Estado, donde una proporción elevada de trabajadores viv del autoempleo o empleos eventuales, y carece de todo tipo de prestaciones sociales y respaldos estatales. Para algunos autores la informalidad es el resultado de la incapacidad del sistema capitalista de absorber y dar empleo a ciertos sectores de la población, relacionando migración, crisis económicas y tasas de desempleo, mientras otros autores señalan las conexiones existentes entre el sector formal-informal a través de empresas y talleres autónomos como estrategias del sector formal para minimizar costes (De la Peña, 1993, 2000; Escobar 1986; Palacios, 1990).

${ }^{7}$ Como una posible opción de subsistencia, los mixtecos que habitan en la Colonia Brisas de Chapala de Tlaquepaque, han formado una banda musical llamada "La Concordia" con miembros parentales masculinos de diferentes generaciones, Los hijos tienen una socialización familiar asociada a la música porque desde pequeños se les enseña a tocar algún instrumento para que cuando crezcan puedan ser parte de la banda. No obstante este grupo de inmigrantes posee niveles altos de marginalidad y pobreza. La venta ambulante no permite la subsistencia económica del grupo y la banda es más un elemento de identificación que de subsistencia, por lo que algunos mixtecos han tenido que recurrir a mendigar por las calles.

${ }^{8}$ Se trata de indígenas tsotsiles que vivían en la ciudad de San Cristóbal de Las Casas, Chiapas. Actualmente, se dedican a la venta de blusas, manteles individuales, tapetes y otros productos textiles elaborados en Los 
Altos de Chiapas y Guatemala, y realizan continuos viajes a Chiapas para traer nueva mercancía. Son un grupo de parientes muy reducido que ha conseguido buenos puestos de venta en las zonas turísticas de Tlaquepaque y en el centro de Guadalajara.

${ }^{9}$ Las redes y cadenas migratorias han sido utilizadas en migración para explicar la trayectoria desde un lugar a otro, la llegada y el apoyo hacia los nuevos inmigrantes, la información que reciben para empezar a conocer la ciudad de destino, los contactos y apoyos materiales, que se hacen posibles por las relaciones personales que refuerzan los inmigrantes, las relaciones de poder que se tejen entre género generaciones, y de un circuito constante migratorio, entre origen y destino de personas, pero también de todo tipo de recursos, objetos, informaciones, identificaciones, ideas, normas y valores.

${ }^{10}$ De la Peña (1984) establece dos ámbitos del parentesco: organización e ideología, para diferenciar las normas ideales y las prácticas reales que coordinan las actividades y definen a cada miembro en términos del parentesco, que pueden entrar en contradicción cuando uno o los dos ámbitos sufren transformaciones.

${ }^{11}$ La adopción se realiza por varias circunstancias: niños que llegan a vivir a la ciudad porque sus familiares de Pama no se hacen cargo de ellos, muchachos que prefieren seguir a sus paisanos para intentar conseguir dinero propio, o acuerdos que se hacen entre familias en Pamatácuaro, que implican que una familia se haga cargo de los hijos de otra. Este tipo de adopción implica una distinción clara entre los hijos de sangre y los que no lo son, lo que se traduce en aceptar dentro de un seno familiar a un miembro que no tiene relaciones parentales pero sí deberes y obligaciones.

12 Un análisis sobre los nuevos arreglos domésticos aparece en María Eugenia D’Aubeterre (2000), quien ha denominado unidades domésticas transnacionales a familias de migrantes y no migrantes que conforman grupos familiares con deberes y obligaciones que establecen entre dos o más espacios migratorios.
${ }^{13}$ Durante el trabajo de campo, encontré varias familias de inmigrantes comerciantes que habían empezado a incursionar en el comercio en la ciudad a partir de una red específica parental o paisanal, sin tener relación con los primeros pioneros mayoristas. Las redes se han ido diversificando a medida que el grupo ha ido aumentando de tamaño No obstante, todos coincidieron en la existencia de un pionero principal e importante que abrió la primera tienda mayorista y ofreció ayuda a los siguientes inmigrantes.

${ }^{14}$ La endogamia es una práctica común entre los grupos étnicos de México, entendida como las alianzas que se establecen entre individuos de la misma condición étnica y clase social Algunos autores han justificado su permanencia en los procesos migratorios al considerar que la endogamia permite a los inmigrantes seguir siendo una sola comunidad repartida entre varios espacios que evita, a su vez, la dispersión del mismo (Oehmichen, 2001, 2002; Lestage, 1999). Otros, unen la idea de la importancia de mantener y consolidar las relaciones de parentesco entre las familias repartidas en los lugares de origen y de destino (D'Aubeterre, 2000).

${ }^{15}$ En Pamatácuaro las fiestas religiosas están financiadas por un "sistema de cargos", compuesto por 36 mayordomos que asumen la custodia de una imagen religiosa durante tres años, y que supone la inversión de grandes sumas de dinero en la demostración del cargo. En Guadalajara se nombran seis mayordomos en cada barrio donde viven los inmigrantes, que ayudan a recopilar dinero dentro de los espacios migratorios. Este sistema de colaboración comunal de inmigrantes no aparece todavía entre las colonias de inmigrantes dispersas en otras ciudades mexicanas, porque para ello se requiere antigüedad migratoria y una organización interna basada en la jerarquía de ciertos hombres inmigrantes que sustituyan el papel de las autoridades tradicionales comunales.

${ }^{16}$ En la colonia Brisas de Chapala hay un gran descampado en donde se tiraron los desechos materiales y de cadáveres que se sacaron de las explosiones que 
ocurrieron el 22 de abril del año 1992 en el Sector Reforma del municipio de Guadalajara, a causa de una negligencia de la empresa pública Petroleros Mexicanos (PEMEX) que provocó un derrame de 1,200,000,000 de litros de hidrocarburos en el drenaje.

17 Es el caso del Programa Oportunidades, que para algunas mujeres implica un esfuerzo en vano, por los trámites requeridos, los documentos solicitados y por el tiempo que se pierde en el traslado, por lo que muchas prefieren aprovechar la jornada para vender en los tianguis. En cambio, en otros casos, como cuando hay conflicto y violencia conyugal, algunas mujeres piden atención y ayuda a las patrullas policiales y los servicios médicos, lo que demuestra que la utilización de ciertas instituciones les sirve a las mujeres para negociar mayores ventajas en la ciudad.

18 Existen alrededor de 250 tianguis semanales que se distribuyen y se instalan siguiendo una ruta semanal en distintos puntos de ZMG. Cada día hay aproximadamente 30 tianguis que varían en tamaño o número de calles que ocupan para la venta y que ofrecen todo tipo de mercancías, mayoritariamente frutas y verduras y otros artículos como ropa, utensilios de cocina, discos compactos y calzado, entre otros. Los lugares en donde se abastecen los tiangueros son, mayoritariamente, la Central de Abastos y los mercados Felipe Ángeles, Corona y Alcalde (Padilla y Niembro, 1986).

${ }^{19}$ La lengua purépecha es utilizada frecuentemente en la ciudad entre los inmigrante adultos como un medio de comunicación e identificación, a la vez que se convierte en una especie de código secreto en los espacios comunitarios y urbanos de los inmigrantes en la ciudad. Pero entre los jóvenes y los niños que ya nacieron en la ciudad, el español se ha convertido en la primera lengua de uso, y la lengua purépecha ya no es el medio de comunicación principal, sino uno secundario que se utiliza en los espacios comunitarios urbanos. De hecho, para los inmigrantes, el uso del español comporta mayores beneficios en la ciudad en su contacto con instituciones y campos laborales, por lo que se están produciendo situaciones de desplazamiento de una lengua por otra en el mundo urbano, y conflictos lingüísticos entre generaciones y en espacios diversos.

${ }^{20}$ Otra posibilidad para conseguir dineroes la participación en rifas o tandas que han organizado algunos paisanos para juntar un fondo de dinero para que cada semana lo recoja uno de los participantes. Las tandas en un sistema de ahorro que implica confianza y lealtad entre los participantes.

${ }^{21} \mathrm{El}$ consumo se considera una práctica social que ofrece significados a las mercancías que se intercambian y a las personas que se involucran. Douglas e Isherwood (1979) hablan de las mercancías como objetos dentro de un tráfico cultural que poseen significados y propósitos sociales. Las mercancías sirven para establecer relaciones sociales y el consumo para dar sentido a la interacción social a través de la posesión de objetos que sirven para significar el mundo. Se escogen algunas mercancías para dar sentido y comunicarse dentro de un espacio socialmente clasificado. El consumo, para los autores, es un proceso activo en el cual todas las categorías son continuamente redefinidas dentro de un marco estructurado de significados.

${ }^{22}$ Las tres fiestas más destacadas para la visita de los inmigrantes son: el Carnaval, en el mes de febrero; la Fiesta de El Señor del Calvario, en la tercera semana de julio, y la fiesta de Cristo Rey en la tercera semana de noviembre. También pueden acudir al jueves y viernes de Semana Santa, al Corpus Christi y al Día de Muertos los días 1 y 2 de noviembre para visitar a los difuntos en el cementerio local y, en algunos casos, decorar un pequeño altar con algunos alimentos o bebidas.

${ }^{23}$ En Guadalajara se han nombrado cargueros para el cuidado de la copia de la Virgen de la Inmaculada Concepción de Cocucho, localidad que pertenece al municipio de Charapan. En el templo de San Bartolomé de Cocucho, cuya construcción data del siglo XVI, se guarda la auténtica de la Virgen, que tiene fama de ser 
milagrosa y de conceder muchos favores. Cada 28 de enero la imagen sale en procesión y muchos habitantes de alrededor realizan una peregrinación hacia Cocucho para festejar a la Virgen y participar en las fiestas en su honor. En Pamatácauro, la peregrinación reúne a inmigrantes y no inmigrantes en su camino hacia la comunidad de donde es originaria la Virgen. Los paisanos de la ciudad cuentan que fueron los mayordomos de Cocucho que ofrecieron la copia de la imagen a algún inmigrante de Guadalajara para que los seguidores pudieran también hacer sus peticiones en la ciudad. Los cargueros que se nombran en la ciudad poseen este cargo durante tres años y dejan a la Virgen en casas particulares según las peticiones que llegan.

24 Alfred Gell (1991) considera que el consumo es una forma de acción simbólica que consiste en la apropiación de objetos que se vinculan con referentes personales, con insignias de identidades y con signos de relaciones y obligaciones específicas, como una forma de incorporar el producto a la definición del ser social. Esto no quiere decir que todos los objetos consumidos se conviertan en insignias, sino que algunos y según el contexto referido ofrecen la posibilidad de demostrar la identidad social del consumidor. En este caso, entre los purépechas escogen unos objetos y no otros para extender el significado social de prestigio en la localidad de origen; por ejemplo, construir una casa con luz cuando la electricidad es deficiente, hacer puertas de garaje sin acceso para los automóviles, colocar cisternas donde nunca llega el agua, o comprar televisores y video caseteras que no pueden ser vistos o utilizados, entre otros, que demuestran más la riqueza del inmigrante que la utilidad del mismo.

\section{Bibliografía}

Bayona, Eugenia (2009), "La ciudad como oportunidad y peligro. La comunidad inmigrante de comerciantes purépechas en Guadalajara", Tesis doctoral, México: Ciesas.
Camus, Manuela (1998), "Ser indio en la Terminal", en Alteridades, vol. 15, año 8, pp. 131-145.

Cohen, Abner (2004), Custom and Politics in Urban Africa. A study of Hausa Migrants in Yoruba towns. London and New Cork: Routledge.

D’Aubeterre B., María Eugenia (2000), El pago de la novia. Matrimonio, vida conyugal y prácticas transnacionales en San Miguel Acuexcomac, Puebla, México: El Colegio de Michoacán/Benemérita Universidad Autónoma de Puebla/Instituto de Ciencias Sociales y Humanidades.

De la Peña, Guillermo (1984), "Ideology and Practice in Southern Jalisco: Peasants, Rancheros and Urban Entrepreneurs", en T. Smith, Raymond (Ed.), Kinshis Ideology and practice in latin America, USA: The University of North Carolina Press, pp. 204-236.

De la Peña, Guillermo (1993), "La antropología mexicana y los estudios urbanos”, en Arizpe, Lourdes (Coord.), Antropología breve de México, México: Academia de Investigación Científica/CRIM-UNAM.

De la Peña, Guillermo (2000), "Corrupción e informalidad", en Lomnitz, Claudio (coord.), Vicios públicos, virtudes privadas: la corrupción en México, México: CIESAS/Miguel Ángel Porrúa.

Douglas, Mary y Baron Isherwood (1979), El mundo de los bienes. Hacia una antropología del consumo, México: Consejo Nacional para la Cultura y las Artes/Grijalbo.

Escobar, Agustín (1986), "Patrones de organización social en el mercado de trabajo manual en Guadalajara”, en De la Peña, Guillermo y Agustín Escobar (Comps.), Cambio regional, mercado de trabajo y vida obrera en Jalisco, Guadalajara: El Colegio de Jalisco.

Gell, Alfred (1991), "Los recién llegados al mundo de los bienes: el consumo entre los gondo muria", en Appadurai, Arjun (Ed.). La vida social de las cosas. Perspectiva cultural de las mercancías, México: Editorial Grijalbo, pp. 143-175.

González de la Rocha, Mercedes (1986), Los recursos de la pobreza. Familias de bajos ingresos en Guadalajara, Guadalajara: El Colegio de Jalisco/CIESAS/SEP. 
Instituto Nacional de Estadística, Geografía e Historia (1990), XI Censo General de Población y Vivienda, México: INEGI.

Instituto Nacional de Estadística, Geografía e Historia (2000), XII Censo General de Población y Vivienda, México: INEGI.

Instituto Nacional de Estadística, Geografía e Historia (2005), Conteo de Población y Vivienda, México: INEGI.

Lestage, Francoise (1999), "Diseñando nuevas identidades. Las uniones matrimoniales entre los migrantes mixtecos en Tijuana”, en Mummert, Gail (Ed.), Fronteras fragmentadas, Zamora: El Colegio de Michoacán, pp. 421-436.

Lomnitz, Larissa (1975), Cómo sobreviven los marginados, México: Siglo XXI.

Lomnitz, Larissa (2001), Redes sociales, cultura y poder. Ensayos de antropología latinoamericana, México: Miguel Ángel Porrúa Grupo Editorial.

Martínez-Casas, Regina (2000), "La presencia indígena en Guadalajara: los vendedores de la plaza tapatía", en Rojas, Rosa y Agustín Hernández (Coords.), Rostros y palabras. El indigenismo en Jalisco, México: Instituto Nacional Indigenista, pp. 41-62.

Martínez-Casas, Regina (2007), Vivir invisibles. La resignificación cultural entre los otomíes urbanos de Guadalajara, México: CIESAS.

Oehmichen, Cristina (2001), "Mujeres indígenas migrantes en el proceso de cambio cultural. Análisis de las normas de control social y relaciones de género en la comunidad extraterritorial", Tesis de doctorado en Antropología, México: Facultad de Filosofía y
Letras de la Universidad Nacional Autónoma de México.

Oehmichen, Cristina (2002), "Parentesco y matrimonio en la comunidad extendida: el caso de los mazahuas", en Alteridades, núm. 24, pp. 61-74.

Padilla, Cristina (1997), Todo queda en familia. El mercado de Abastos de Guadalajara, Guadalajara: Universidad de Guadalajara/Centro Universitario de Ciencias Sociales y Humanidades.

Padilla, Cristina y Laura Niembro (1986), "La comercialización de frutas y hortalizas en la zona metropolitana de Guadalajara”, en De la Peña, Guillermo (Comp.), Crisis, conflicto y sobrevivencia. Ensayos sobre la sociedad urbana de México, Guadalajara: Universidad de Guadalajara/ CIESAS, pp. 303-316.

Palacios, Juan José (1990), "La economía subterránea de América Latina: ¿alternativa obligada de supervivencia o mecanismo ilegal de producción?", en De la Peña, Guillermo (Comp.), Crisis, conflicto y sobrevivencia. Ensayos sobre la sociedad urbana de México, Guadalajara: Universidad de Guadalajara/CIESAS, pp. 119-138.

Wolf, Eric R. (1981), "Comunidades corporadas cerradas de campesinos en Mesoamérica y Java central”, en Llobera, J. R. (Comp.), Antropología económica. Estudios etnográficos, Barcelona: Anagrama, pp. 81-98.

Wolf, Eric R. (1999), "Relaciones de parentesco, de amistad y de patronazgo en las sociedades complejas", en Banton, Michael (Comp.), Antropología de las sociedades complejas, Madrid: Alianza Universidad, pp. 19-39. 
Mapa 1. Mapa de la Zona Metropolitana de Guadalajara.

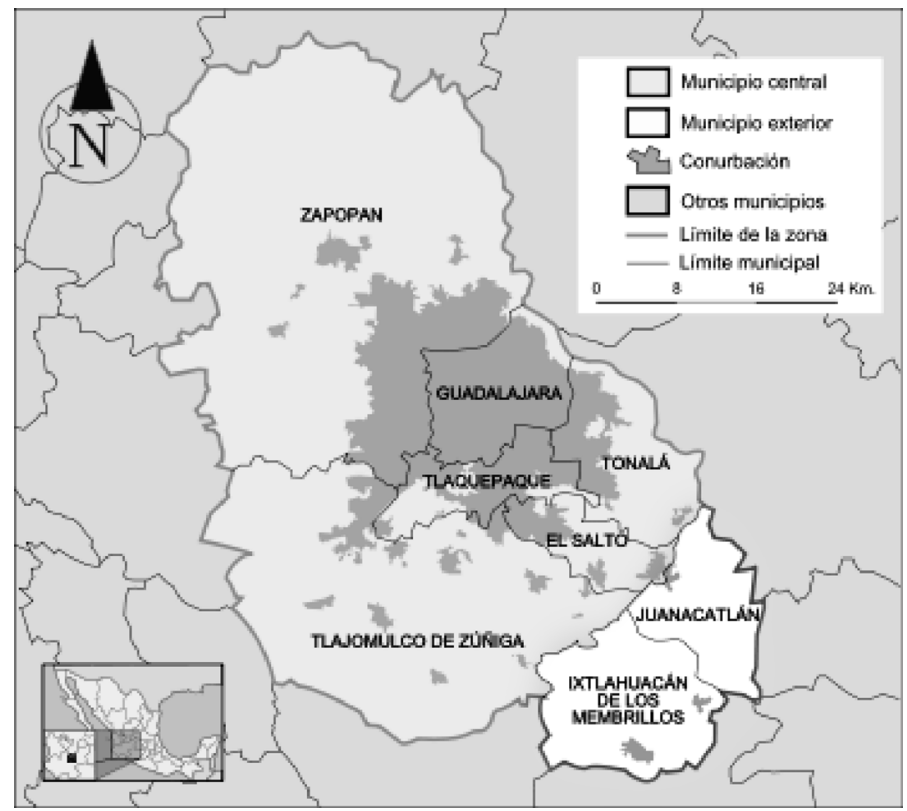

Cuadro 1. Población de 5 y más años hablante de lengua indígena según lengua y municipio; año 2000

\begin{tabular}{|c|c|c|c|c|c|c|}
\hline & GUADALAJARA & TLAQUEPAQUE & TONALÁ & ZAPOPAN & $\begin{array}{c}\text { TOTAL } \\
\text { ZMG }\end{array}$ & $\%$ \\
\hline NÁHUATL & 1.494 & 199 & 186 & 2.482 & 4.361 & $24 \%$ \\
\hline PURÉPECHA & 620 & 458 & 164 & 1.071 & 2.313 & $13 \%$ \\
\hline LENGUAS MIXTECAS & 538 & 187 & 114 & 193 & 1.032 & $6 \%$ \\
\hline OTOMÍ & 233 & 567 & 24 & 141 & 965 & $5 \%$ \\
\hline LENGUAS ZAPOTECAS & 210 & 49 & 35 & 460 & 754 & $4 \%$ \\
\hline MAZAHUA & 123 & 91 & 19 & 279 & 512 & $3 \%$ \\
\hline HUASTECO & 142 & 44 & 12 & 297 & 495 & $3 \%$ \\
\hline HUICHOL & 173 & 32 & 43 & 163 & 411 & $2 \%$ \\
\hline MAYA & 103 & 22 & 29 & 68 & 222 & $1 \%$ \\
\hline OTRAS LENGUAS INDÍGENAS & 444 & 137 & 95 & 560 & 1.236 & $7 \%$ \\
\hline NO ESPECIFICADO & 2.523 & 771 & 585 & 1.634 & 5.513 & $31 \%$ \\
\hline HABLANTES LENGUA INDÍGENA & 6.603 & 2.557 & 1.306 & 7.348 & 17.814 & \\
\hline
\end{tabular}

Fuente: elaboración propia a partir de INEGI. II Conteo de Población y Vivienda 2000. 
Cuadro 2. Población de 5 y más años hablante de lengua purépecha según municipio; serie temporal

\begin{tabular}{|l||c||c||c||c||c|}
\hline \hline \multicolumn{1}{|c||}{ AÑO } & GUADALAJARA & TLAQUEPAQUE & TONALÁ & ZAPOPAN & TOTAL ZMG \\
\hline \hline 1990 & 669 & 149 & 32 & 447 & 1.297 \\
\hline \hline 2000 & 620 & 458 & 164 & 1.071 & 2.313 \\
\hline 2005 & 535 & 513 & 171 & 1.406 & 2.625 \\
\hline \hline
\end{tabular}

Fuente: elaboración propia a partir de INEGI. II Conteo de Población y Vivienda 2000.

Caudro 3. Población de 5 y más años hablante de lengua indígena según lengua y municipio; año 2005

\begin{tabular}{|c|c|c|c|c|c|c|}
\hline & GUADALAJARA & TLAQUEPAQUE & TONALÁ & ZAPOPAN & $\begin{array}{c}\text { TOTAL } \\
\text { ZMG }\end{array}$ & $\%$ \\
\hline NÁHUALT & 1.491 & 265 & 201 & 3.560 & 5.517 & $28 \%$ \\
\hline PURÉPECHA & 535 & 513 & 171 & 1.406 & 2.625 & $13 \%$ \\
\hline LENGUAS MIXTECAS & 461 & 170 & 154 & 256 & 1041 & $5 \%$ \\
\hline OTOMÍ & 177 & 576 & 14 & 107 & 874 & $4 \%$ \\
\hline LENGUAS ZAPOTECAS & 210 & 44 & 22 & 523 & 799 & $4 \%$ \\
\hline HUASTECO & 131 & 65 & 16 & 431 & 643 & $3 \%$ \\
\hline MAZAHUA & 91 & 88 & 79 & 377 & 635 & $3 \%$ \\
\hline HUICHOL & 131 & 58 & 42 & 233 & 464 & $2 \%$ \\
\hline TOTONACA & 57 & 49 & 17 & 177 & 300 & $2 \%$ \\
\hline MAYA & 63 & 19 & 22 & 53 & 157 & $1 \%$ \\
\hline OTRAS LENGUAS INDÍGENAS & 326 & 114 & 57 & 552 & 1.049 & $5 \%$ \\
\hline NO ESPECIFICADO & 2.288 & 864 & 654 & 2.041 & 5.847 & $29 \%$ \\
\hline HABLANTES LENGUA INDÍGENA & 5.961 & 2.825 & 1.449 & 9.716 & 19.951 & \\
\hline
\end{tabular}

Fuente: elaboración propia a partir de INEGI. II Conteo de Población y Vivienda 2005. 